\title{
Optical properties of aerosol mixtures derived from sun-sky radiometry during SAMUM-2
}

\author{
By C. TOLEDANO ${ }^{1,3 *}, \mathrm{M}_{\text {. WIEGNER }}{ }^{1}, \mathrm{~S}$. GRO ${ }^{1}{ }^{1}$, V. FREUDENTHALER ${ }^{1}, \mathrm{~J}_{\text {. GASTEIGER }}{ }^{1}$, \\ D. MÜLLER ${ }^{2,5}$, T. MÜLLER ${ }^{2}$, A. SCHLADITZ ${ }^{2}$, B. WEINZIERL ${ }^{6}$, B. TORRES ${ }^{3}$ and \\ N. T. O'NEILL ${ }^{4}, \quad{ }^{1}$ Meteorological Institute, Ludwig-Maximilians-Universität, Theresienstr. 37, Munich, \\ Germany; ${ }^{2}$ Leibniz Institute for Tropospheric Research, Permoserstr. 15, Leipzig, Germany; ${ }^{3}$ Group of Atmospheric \\ Optics, Valladolid University, Valladolid, Spain; ${ }^{4}$ CARTEL, Université de Sherbrooke, Sherbrooke, Canada; \\ ${ }^{5}$ Atmospheric Remote Sensing Laboratory, Gwangju Institute of Science and Technology, Gwangju, South Korea; \\ ${ }^{6}$ Deutsches Zentrum für Luft- und Raumfahrt (DLR), Institut für Physik der Atmosphäre, Oberpfaffenhofen, 82234 \\ Wessling, Germany
}

(Manuscript received 7 November 2010; in final form 10 June 2011)

\begin{abstract}
The SAMUM-2 experiment took place in the Cape Verde islands in January-February 2008. The colocated ground-based and airborne instruments allow the study of desert dust optical and microphysical properties in a closure experiment. The Meteorological Institute of the University of Munich deployed one sun-sky photometer and two tropospheric lidar systems. A travelling AERONET-Cimel sun-sky radiometer was also deployed. During the measurement period the aerosol scenario over Cape Verde mostly consisted of a dust layer below $2 \mathrm{~km}$ and a smoke-dust layer above 2-4 km a.s.l. The Saharan dust arrived at the site from the NE, whereas the smoke originated in the African equatorial region. This paper describes the main results of the Sun photometer observations, supported by lidar information. An analysis of the variations in the aerosol optical depth (AOD) in the range 340-1550 nm, the Ångström exponent, volume size distributions and single scattering albedo is presented. The aerosol mixtures are analysed by means of the fine mode fraction of the AOD provided by the sun-sky inversion data and the Spectral Deconvolution Algorithm. The mean AOD $(500 \mathrm{~nm})$ was 0.31 , with associated low Ångström exponent of 0.46 . Several types of events were detected within the data set, with prevalence of dust or mixtures as characterized by the Ångström exponents of extinction and absorption and the fine mode fraction. Aerosol properties derived from sunphotometry were compared to in situ measurements of size distribution, effective radius and single scattering albedo.
\end{abstract}

\section{Introduction}

The effect of atmospheric aerosols on climate remains one of the largest radiative forcing uncertainties according to the latest IPCC report (Solomon et al., 2007). The large temporal variability and the characterization of horizontal and vertical distributions, aerosol mixtures and absorptive properties constitute difficulties in the evaluation of the aerosol direct radiative forcing (Myhre, 2009; Eck et al., 2010). Aerosol effects on the biological and hydrological cycles and human health are also important considerations.

Mineral dust is one of the main components of the atmospheric aerosol and its origin is mostly natural (about 80\%). The Sahara

\footnotetext{
* Corresponding author.

e-mail: toledano@goa.uva.es

DOI: $10.1111 /$ j.1600-0889.2011.00573.x
}

and Sahel regions are the main source of natural dust in the northern hemisphere (Goudie and Middleton, 2001). The estimated radiative forcing by (anthropogenic) dust is $-0.1 \pm 0.2 \mathrm{~W} \mathrm{~m}^{-2}$ (Solomon et al., 2007). Biomass burning is a significant source of tropospheric aerosol in various regions like central Africa, producing surface cooling and atmospheric warming aloft, with a mean global radiative forcing of $0.03 \pm 0.12 \mathrm{~W} \mathrm{~m}^{-2}$. However forcing efficiencies (by unit of aerosol optical depth, AOD) can be as large as tens or hundreds $\mathrm{W} \mathrm{m}^{-2}$, therefore local and regional aerosol effects can be severe, the sign of the forcing depending on the aerosol type and distribution, especially over clouds or bright surfaces (Randles and Ramaswamy, 2010). The assessment of the aerosol radiative effects relies on accurate knowledge of key optical properties, like AOD, single scattering albedo and asymmetry parameter (Dubovik et al., 2002).

With marked seasonality dependence and displaying coarsely opposing radiative effects, these two aerosol components are 
emitted into and transported within the atmosphere. In the particular case of the North African winter season, smoke from large number of fires occurring in the Sahelian and Sudaninan zones mixes with desert dust from the Saharan desert (Eck et al., 2010; Pinker et al., 2010) and the mixture is transported over the Atlantic towards South America and the Caribbean sea (Prospero et al., 2002; Kaufman et al., 2005; Liu et al., 2008).

Over the past few years different field experiments were carried out in order to investigate the optical properties of mineral dust: PRIDE (Reid et al., 2003), SAFARI (Haywood et al., 2003), SHADE (Tanré et al., 2003), DABEX (Haywood et al., 2008) and DODO (McConnell et al., 2008). At the same time, ground-based networks and satellite observations have provided long-term data sets of aerosol properties (Holben et al., 2001; Remer and Kaufman, 2006). Valuable data sets of optical and microphysical properties have been derived for several West African sunphotometer sites in the Aerosol Robotic Network (AERONET, Holben et al., 1998); these sites are mostly operated by the PHOTONS group (http://loaphotons.univ-lille1.fr/photons)).

The Saharan Mineral Dust Experiment (SAMUM) is a 7-yr project that involves a variety of research groups. Within SAMUM two major field campaigns have been carried out in order to investigate the desert dust properties in a so-called closure experiment (Heintzenberg, 2009; Ansmann et al., 2011). The first campaign, carried out in Morocco in 2006, was close to the dust sources (Heintzenberg, 2009). The second campaign, which is the subject of the present paper, took place in Cape Verde in January-February 2008. Its purpose was to study the properties of dust transported over the Atlantic and the mixing of dust with biomass burning, marine or anthropogenic aerosols. Due to the predominant eastern flow in winter, the Cape Verde islands are in the path of the Saharan dust plumes crossing over the Atlantic at low altitudes. Furthermore, biomass burning aerosols originating in West-central Africa also cross over Cape Verde under certain meteorological conditions (Ansmann et al., 2011; Knippertz et al., 2011).

The Sun photometer observations during SAMUM-1 showed a predominance of aerosols characterized by the optical properties of pure dust (Toledano et al., 2009; von Hoyningen-Huene et al., 2009). A comparison of AERONET inversion products with in situ measurements of dust optical and microphysical properties was also carried out during this experiment (Müller et al., 2010a,b). The comparison was not satisfactory for key parameters, such as the particle size distribution and the complex refractive index. An analysis of this important issue currently continues for dust-dominated SAMUM-1 data acquired using with several instruments and involving the modelling (Otto et al., 2009) of sky radiances produced by non-spherical particles.

The aim of this paper is to investigate the Sun photometer observations acquired during the SAMUM-2 campaign in Praia (Cape Verde). During this campaign Saharan dust was observed relatively far from the sources, after 3-5 d of transport, see Knippertz et al. (2011); therefore it is possible that the observed dust properties are different than in SAMUM-1. The properties of dust mixtures with biomass burning, anthropogenic pollution and sea salt are also considerations, which lie within the scope of this study. Emphasis is placed to the identification of the aerosol type, the absorptive properties and the information contained in the wavelength dependencies of optical properties.

It could be claimed that columnar information provided by Sun photometers cannot be used to discriminate the properties of a single aerosol type when several aerosol types are mixed and structured in layers (as occurred during SAMUM-2). Our point of view is that the SAMUM-2 experiment is an excellent opportunity to evaluate how pure aerosol types and mixtures are detected using Sun photometers. Ground-based Sun photometer networks like AERONET, PFR-GAW or SKYNET provide global coverage and long-term data sets, whose interpretation can be largely improved by an analysis of aerosol mixtures in well-defined conditions (such as was the case during the SAMUM experiment). The correct analysis of key parameters like the Ångström exponent (AE), fine mode fraction, single scattering albedo (SSA) or absorption Ångström exponent (AAE) and their associated uncertainties, can provide aerosol type derivation from remote sensing instruments, both from ground and space (Bergstrom et al., 2007; Eck et al., 2010; Russell et al., 2010).

The colocated in situ observation of optical and microphysical properties, can also be compared with the Sun photometer inversion products. Such results can, in turn, be compared with previous SAMUM-1 research (Müller et al., 2010a,b), that demonstrated important agreements and disagreements between the in situ observations and the AERONET inversion-derived properties.

In Section 2, the characteristics of the measurement site and a description of the instrumentation are provided. Section 3 summarizes the methodology of the analysis and Section 4 describes the results; these are divided into subsections on AOD (Section 4.1), inversion derived properties (Section 4.2) and comparison with in situ observations (Section 4.3). Finally, the conclusions are summarized in section 5 .

\section{Site of measurements and instrumentation}

\subsection{Site of measurements}

The SAMUM-2 campaign was carried out at Praia (Sao Vicente island, Cape Verde). Measurements were performed from January 11 to February 14, 2008. All ground-based instruments were deployed at Praia airport $\left(14.9^{\circ} \mathrm{N}, 23.5^{\circ} \mathrm{W}, 75 \mathrm{~m}\right.$ above sea level). The location of Praia is depicted in Fig. 1, as well as the SAMUM-1 sites (Ouarzazate and Zagora) and the AERONET sites 'Capo Verde' (located on Sal island, 200 km north of Praia, also in Cape Verde), 'Dakar' (Senegal), 


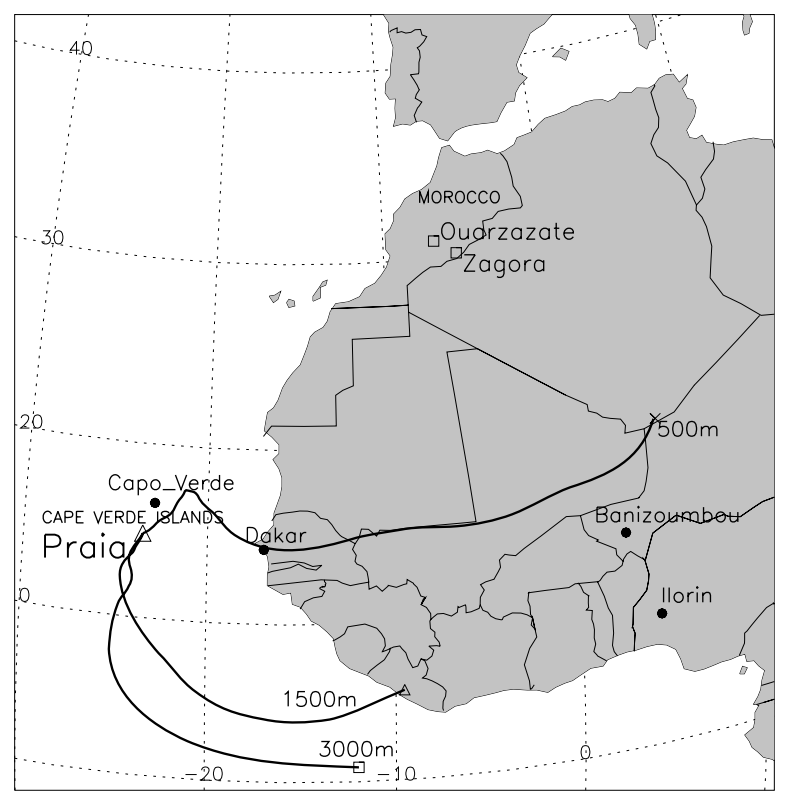

Fig. 1. Location of Praia (Cape Verde), the ground-based measurement site of the SAMUM-2 campaign. Other relevant locations during SAMUM-2 campaign like Dakar are also indicated, as well as the AERONET sites Capo Verde (in Sal island, Cape Verde) and Ilorin (Nigeria). The 5-d back trajectories on 25 January 2008, 00UTC calculated with the HYSPLIT model at 500, 1500 and 3000 m (ending altitudes above ground level) are displayed.

Banizoumbou (Niger) and 'Ilorin' (Nigeria). The distance between Praia and the African continent is about $650 \mathrm{~km}$.

The site had a completely free horizon and no obstacles towards the northeast, the direction of the predominant flow at ground level. The nearest town to the airport has about 6000 inhabitants and is located to the southwest. An overview of the meteorological conditions is provided by Knippertz et al. (2011). The northeasterly wind was persistent and dust deposition was intense on the optical instrumentation (typically the optical instruments had to be cleaned daily).

A climatological analysis of sunphotometry data for this area was very helpful in determining the suitability of the site and to assess whether the measurements correspond to typical conditions or some extraordinary event. Holben et al. (2001) report high optical depth for the 'Capo Verde' site throughout the year. The 12-yr climatology exhibits maximum AOD $(500 \mathrm{~nm})$ of 0.52 in June-July, with associated Ångström exponent of 0.16 , and minimum AOD of 0.25 in November $(\mathrm{AE}=0.40)$. The long-term mean values for January-February, the months of the SAMUM-2 campaign, are $\operatorname{AOD}(500 \mathrm{~nm})$ of 0.29 with associated Ångström exponent of 0.30 .

\subsection{Instrumentation}

During the SAMUM-2 campaign, a comprehensive set of aerosol instruments was deployed at a single site: these included state- of-the-art lidars, in situ samplers, optical instrumentation and Sun-sky radiometers (both ground-based and aircraft-based). For details, see the papers of this Special Issue in Tellus for SAMUM-2. A summary of instruments and references is provided by Ansmann et al. (2011).

The Meteorological Institute of the Ludwig-Maximilian University of Munich (MIM) deployed several active and passive remote sensing instruments: the SSARA Sun-sky photometer, a UV broadband radiometer, a Microtops and two multiwavelength lidar systems, POLIS and MULIS (Freudenthaler et al., 2009; Groß et al., 2011a,b). In addition, a Cimel sun photometer belonging to the AERONET network was also in operation during this campaign.

The Sun-Sky Automatic RAdiometer (SSARA, Toledano et al., 2009), manufactured at MIM, simultaneously collects direct solar irradiances in 12 channels ranging from 340 to $1550 \mathrm{~nm}$. Sky radiances in the solar almucantar are measured at 440,780 and $1030 \mathrm{~nm}$. The sampling interval is $2 \mathrm{~s}$ for the direct Sun measurements. The (fixed solar zenith angle, SZA) almucantar scans are performed at $5^{\circ} \mathrm{SZA}$ intervals for SZA $>60^{\circ}$ in the morning and evening. The better amplification in the UV channels compared to SAMUM-1 (Toledano et al., 2009), permitted us to determine the AOD in the UV channels at air masses $<7.5$.

The AERONET Cimel Sun photometer deployed (number \#90) is a standard model, with nine channels covering the spectral range 340-1020 $\mathrm{nm}$ for the direct Sun measurements, and four channels $(440,670,870$ and $1020 \mathrm{~nm})$ for the sky radiances collected in the almucantar and principal plane configurations. Direct Sun measurements are performed every $15 \mathrm{~min}$ (more frequently at sunrise and sunset) and sky radiances are measured every hour. A full instrument description is provided by Holben et al. (1998).

A description of the MIM lidar systems deployed in SAMUM2 is given by Groß et al. (2011b). They are equipped with elastic and Raman channels and provide backscattering and extinction coefficients and depolarization ratios at three wavelengths (355, 532 and $1064 \mathrm{~nm})$. It must be noted that the POLIS lidar has a very low full overlap ( $100 \mathrm{~m}$ above ground), allowing excellent characterization of the boundary layer (Groß et al., 2011a). The lidars monitored the atmospheric conditions with two measurement sessions a day, typically in the morning and in the late evening, although in special cases they were operated continuously.

\section{Method}

The SSARA direct Sun measurements are used to derive the spectral AOD from 340 to $1550 \mathrm{~nm}$ and the Angström exponent. The methodology was already described in Toledano et al. (2009). It basically duplicates the AERONET version 2 direct Sun algorithm (see AERONET web page). The ozone column was obtained once per day with a Microtops photometer. 
The pre-field calibration of the SSARA was carried out at the Environmental Research Station Schneefernerhaus (2650 m a.s.1., on Zugspitze mountain, Germany). Direct Sun channels were calibrated with the well-known Langley plot method. Sky channels were calibrated with the vicarious method (Li et al., 2008). The post-field calibration was carried out at Izaña Observatory (2372 $\mathrm{m}$ a.s.1., Tenerife, Spain), the calibration centre for the master instruments of the AERONET European subnetworks [RIMA (Spain) and PHOTONS (France)]. The AERONETRIMA integrating sphere was also used to calibrate the sky channels. The two sky calibration procedures (sphere and vicarious) showed differences below 5\%, which is considered the uncertainty of the SSARA sky channels. Direct Sun channel calibration in these high altitude stations are accurate to $1-3 \%$ and the derived optical depths have absolute uncertainty below 0.01-0.03 (larger for shorter wavelengths).

The Cimel data were processed using the AERONET procedure. The usual direct Sun and inversion products (version 2) are available from the AERONET website. The instrument was calibrated before and after deployment in accordance with AERONET protocols. The data fulfilled all quality criteria and were raised to level 2.0 (quality-assured data). The absolute uncertainty ranges from 0.01 in the infrared-visible to 0.02 in the ultraviolet channels. Sky radiance accuracy is $5 \%$.

Two inversion algorithms were applied to the Sun-sky Cimel data, the routine version 2 AERONET inversion for retrieval of dust properties (Dubovik et al., 2006), and a modified version of the Nakajima inversion (Nakajima et al., 1996). We could only apply the Nakajima inversion to the SSARA data (the AERONET inversion is not available to us). From these inversions a set of optical and microphysical aerosol parameters were derived: volume particle size distribution, single scattering albedo, phase function and complex refractive index.

For the Nakajima inversion, the Skyrad version 4.6 retrieval algorithm was used. We, however, replaced (in a similar fashion to Olmo et al. (2008)) the default Mie scattering (spherical particle) kernel file, by a non-spherical kernel based on the T-matrix theory (Mishchenko et al., 1997). A radius interval from 0.05 to $20 \mu \mathrm{m}$ was used. This is slightly larger than the 0.05 to $15 \mathrm{~m}$ radius interval of the AERONET retrieval.

The uncertainty of the AERONET inversion products was described by Dubovik et al. $(2000,2006)$. The reported uncertainties for dust aerosol are as large as $35 \%$ for the size distribution in the $0.1<r<7 \mu \mathrm{m}$ size range, $50 \%$ for the imaginary part of the refractive index and 0.03 absolute error for the single scattering albedo. However Müller et al. (2010a,b) demonstrated that the differences between in situ observations and several AERONET products exceeded the estimated uncertainties in the analysed dust case of SAMUM-1. Therefore, all comparisons and interpretations must be taken with caution.

The spectral deconvolution algorithm (SDA, O'Neill et al., 2003,2008) was applied to the SSARA AODs. This algorithm uses the spectral derivatives of the AOD to separate the AOD into fine and the coarse mode fractions, assuming a bimodal particle size distribution. An extended wavelength version of the SDA, called SDA+, was also applied to the AOD spectra extending from the UV to the $1550 \mathrm{~nm}$ channel (O'Neill et al., 2008). The SDA+ was employed to investigate the coarse mode information which could be retrieved by including the long wavelength channel. For the Mie computations a refractive index of $m=1.53-0.0057 i$ was assumed ('mineral aerosol' from the OPAC climatology at $1550 \mathrm{~nm}$; Hess et al., 1988). This $1550 \mathrm{~nm}$ channel is analogous to the usage of the $1640 \mathrm{~nm}$ channel for some AERONET Cimels such as the one deployed in SAMUM1 (Müller et al., 2010a). The SDA outputs provide the fine mode curvature (spectral derivatives) in addition to the fine and coarse mode optical depths. This curvature is then inserted into a second simple algorithm (O'Neill et al., 2005) for extracting the fine mode effective radius (the algorithm is called FMC for fine mode curvature and the complete process is called the SDA/FMC algorithm). These values of fine-mode effective radius will be compared to the effective radii derived from the Dubovik size distributions and the in situ observations in Section 4.3.

The $(500 \mathrm{~nm})$ SDA outputs for the Cimel data (but not the estimates of fine mode effective radius) as well as the fine mode (Dubovik inversion) fraction of the AOD at various wavelengths are provided by AERONET. The fine mode fraction of the AOD derived from the Dubovik inversion and the SDA can differ to a certain extent (e.g. Eck et al., 2010). One reason for this is that the method for dividing aerosols into fine and coarse modes is different. Sun-sky radiances for the Dubovik inversion are acquired at low frequencies (1 $\mathrm{h}$ while AODs for the SDA are collected at higher frequencies (5-15 $\mathrm{min}$ ).

\section{Results}

The Sun photometer data, including AOD, Ångström exponent and inversion products derived from the almucantar radiances are presented in this section. The latter include particle size distribution, fine mode fraction and absorption properties represented by the absorption Ångström exponent and the single scattering albedo.

The colocated lidar observations during SAMUM-2, together with the meteorological analysis, provide insight into the aerosol properties and their origin. They reveal dust transport from the northeast at low altitudes, below $1.5 \mathrm{~km}$ a.s.l. Above this altitude a mixture of biomass burning smoke with dust, both arriving from the southeast, is detected (Groß et al., 2011b; Knippertz et al., 2011). Over West-central Africa the biomass burning season was active, as shown by the number of fires detected by the MODIS Rapid Response System (see fig. 1 in Ansmann et al., 2011). Depending on the meteorology, on some days only one of the layers was present, allowing a specific type characterization with the Sun photometers. But in most cases (14 of 29 measurement days) both layers were detected with the lidars. 
Fig. 2. Example of lidar profile in Praia (Cape Verde) during SAMUM-2 on 25 January 2008, average 14:00-16:00 UTC. Data from lidar systems POLIS $(355 \mathrm{~nm})$ and MULIS (532 nm): (a) extinction coefficient $\left(\mathrm{km}^{-1}\right)$; (b) linear particle depolarization ratio; (c) extinction Ångström exponent derived for the wavelengths 355 and $532 \mathrm{~nm}$.

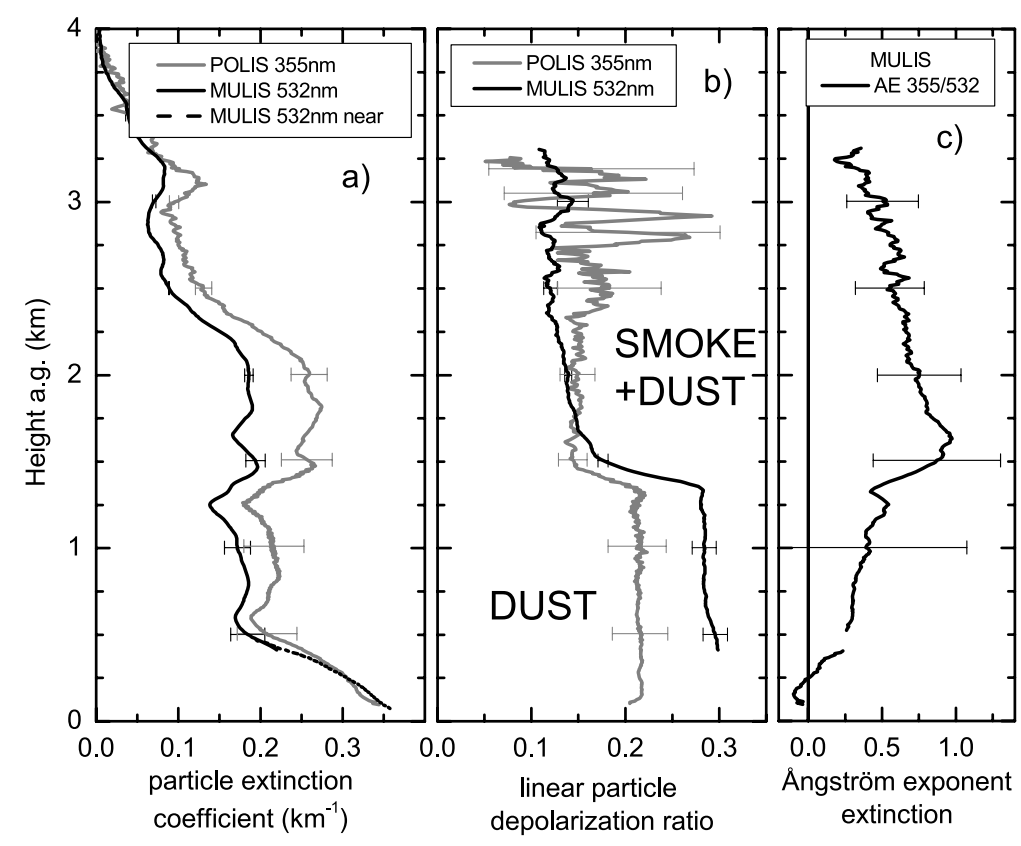

An example of such a multi-layer lidar profile is depicted in Fig. 2, corresponding to 25 January 2008. The 5-d back trajectories on this day, calculated with the HYSPLIT model are shown in Fig. 1. At low levels, the extinction coefficient is nearly wavelength independent (Ångström exponent close to 0) and the particle linear depolarization ratio is about 0.3 (at $532 \mathrm{~nm}$ wavelength); these values indicate the presence of coarse nonspherical particles, i.e. desert dust. Above $1.5 \mathrm{~km}$ the Ångström exponent increases to $0.5-0.95$, indicating a mixture of fine and coarse particles (smoke and dust). In this layer the depolarization ratio is also lower (about 0.15) but still large, and wavelength independent [i.e. the contribution of spherical particles is larger and/or the mean particle size is smaller (Gasteiger et al., 2011)]. A similar layer structure is described for the DABEX campaign in January-February 2006 (Johnson et al., 2008).

\subsection{AOD and Ångström exponent}

The AOD in the 340-1550 nm spectral range was measured from 11 January to 14 February 2008. The two instruments deployed at Praia airport overlapped between 23 January and 9 February,
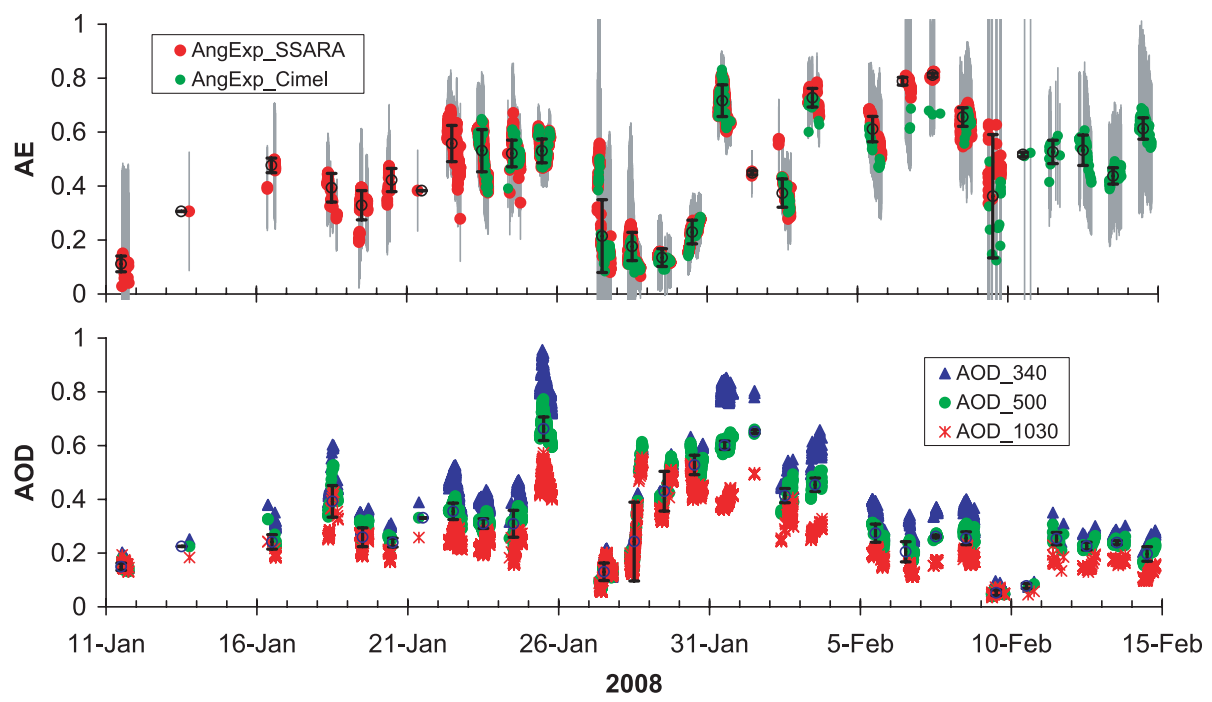

Fig. 3. Time series of AOD (340, 500 and $1030 \mathrm{~nm}$ ) from the SSARA and the Cimel in Praia (Cape Verde) during SAMUM-2 (lower panel); derived Ångström exponent in the range 440-870 nm (upper panel), with error bars in grey. Note the larger AE error bars for lower AOD cases. Daily means with \pm 1 STD are superimposed in black. AERONET data can be downloaded from the AERONET web (site: Praia). SSARA data are available at http://www.meteo.physik.uni-muenchen.de/ stssara/SAMUM2/index.html 


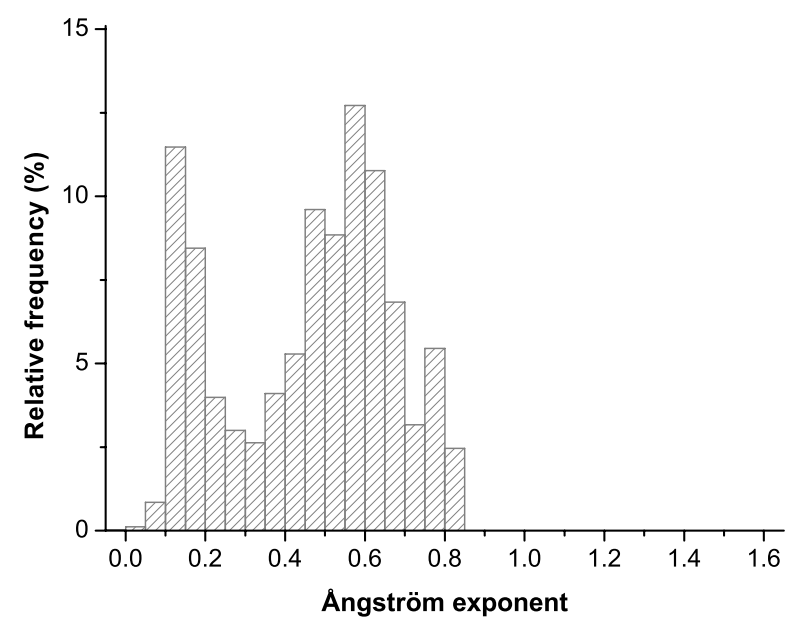

Fig. 4. Frequency histogram of the Ångström exponent from the SSARA (11 January-9 February) and the Cimel (10-14 February) data in Praia (Cape Verde) during SAMUM-2.

with fair AOD agreement (better than 0.01 at $500 \mathrm{~nm}$ and 0.05 at $340 \mathrm{~nm}$ ).

The time series of the AOD at 340, 500 and $1030 \mathrm{~nm}$ as well as the (440-870 nm) Ångström exponent derived from the SSARA are displayed in Fig. 3, as 1-min averages. From 10 to 14 February the data are from the Cimel. In the course of the campaign, the AOD $(500 \mathrm{~nm})$ ranged from 0.04 to 0.74 , with a mean value of 0.31 . The average Ångström exponent was 0.46 , ranging from 0.03 to 0.82 .

The highest AOD values, obtained during short time periods (25 and 31 January), correspond to the simultaneous transport of low level dust, driven by a NE wind, and a mixed type above $2 \mathrm{~km}$ under the influence of a SE wind (according to the lidar and back-trajectories, Fig. 2). On some days (27-30 January) the AOD had almost no wavelength dependence, indicating that desert dust was the predominant aerosol type. The low AOD on 9-10 February resulted from the absence of any transported aerosol layers.
The AE histogram displayed in Fig. 4 shows two modes, therefore two aerosol types with respect to size predominance. The lowest values, around 0.15 , are typical for desert dust and marine aerosols. Marine aerosol particles constitute the background aerosol, as can be expected for a windy island location. The low AE (about $0.2-0.4$ on the two cleanest days of 9-10 February) agree with typical marine aerosol observations (Smirnov et al., 2002). The marine aerosol is masked by transported aerosols on the other measurement days, but it was present in the boundary layer during the entire measurement period (Groß et al., 2011a; Kandler et al., 2011a). However the sea salt contribution to the AOD is small, about $5 \%$ or less during dusty days (Groß et al., 2011a). We found that $28 \%$ of the data was associated with AE values up to 0.3 or hence that approximately $28 \%$ of the data was dust dominated. The second mode of the histogram, around 0.6 , indicates a mixed aerosol type. Given the relatively low AE (always below 0.9), this mixture must contain a significant proportion of coarse particles.

Periods with these predominant types can be identified by means of the AOD and AE. To separate them, a threshold of $\mathrm{AE}=0.3$ for the daily mean was established given the results of the AE histogram (Fig. 4). A summary of the event periods is reported in Table 1. The table also includes the altitude and origin information provided by the lidar and the back-trajectory analysis, as a means of qualitatively appreciating the complementarity between column and height-resolved information. It can be seen that the defined events are almost identical to the periods established by Knippertz et al. (2011). The dust period on 27-30 January can be easily recognized because of the low $\mathrm{AE}$ and high AOD. Before and after this period, the collected sun photometer data exhibit greater AOD wavelength dependence.

The lidars indicate no dust at low levels after 4 February Only the upper layer of smoke+dust was detected. However this observation cannot be confirmed using the sun photometer data, because the upper mixed layer alone still shows low $\mathrm{AE}$ in the range 0.4-0.8. Taking into account that pure (fresh) biomass burning aerosols have an $\mathrm{AE}$ of about 1.5 or larger

Table 1. Summary of event periods within the SAMUM-2 campaign (see text). Periods are distinguished on the basis of the AOD and AE values derived from the sunphotometry. For each period, qualitative information from lidar and back-trajectories provide information about the aerosol origin. For each period, mean and maximum aerosol optical depth (AOD), mean extinction Ångström exponents (AE) calculated in the $440-870 \mathrm{~nm}$ and $380-500 \mathrm{~nm}$ spectral ranges, and fine mode fraction $\left(\eta=\tau_{\text {fine }} / \tau_{\text {total }}\right)$ of the AOD $(500 \mathrm{~nm})$ derived with the SDA algorithm, are given

\begin{tabular}{|c|c|c|c|c|c|c|c|}
\hline Dates & Type & AOD & $\mathrm{AE}_{400-870}$ & $\mathrm{AE}_{380-500}$ & $\mathrm{AOD}_{\max }$ & $\eta_{500 \mathrm{~nm}}$ & Lidar information \\
\hline 11-13 January & Dust & 0.15 & 0.11 & 0.05 & 0.27 & 0.28 & No lidar data. Northeasterly flow \\
\hline 16-25 January & Mixed & 0.38 & 0.51 & 0.41 & 0.77 & 0.43 & Two-layer structure. Dust below $1 \mathrm{~km}$, mixed above \\
\hline 27-30 January & Dust & 0.29 & 0.19 & -0.02 & 0.61 & 0.33 & Only dust, layer below $2 \mathrm{~km}$. \\
\hline 31 Jan-8 February & Mixed & 0.39 & 0.66 & 0.48 & 0.66 & 0.47 & $\begin{array}{l}\text { Two-layer structure until } 4 \text { February } \\
\text { After } 5 \text { February only upper layer from the SE }\end{array}$ \\
\hline 9-10 February & Marine & 0.05 & 0.44 & 0.07 & 0.08 & 0.31 & Clean marine background \\
\hline 11-14 February & Mixed & 0.22 & 0.55 & 0.39 & 0.31 & 0.43 & Only upper layer of mixed aerosol \\
\hline
\end{tabular}


Fig. 5. Scatter plot of Ångström exponent vs. aerosol optical depth $(500 \mathrm{~nm})$ during SAMUM-2, with colours indicating different aerosol types derived from sun photometer and lidar. In grey, pure dust observations of SAMUM-1 in Morocco. In violet, biomass burning aerosol observations from the AERONET site Los Fierros, Bolivia (Holben et al., 2001).

(Eck et al., 1999; Dubovik et al., 2002), and given the AE observed with Sun photometer and lidar, the aerosol arriving at Cape Verde from the biomass burning area around Nigeria, must have consisted of both smoke and dust. The SAMUM-2 data displayed in the AE-AOD scatter plot of Fig. 5 are far from the biomass burning sample data for the Los Fierros, AERONET site, Bolivia (Holben et al., 2001). The data of this second campaign were classified using information on the layer structure and origin provided by the lidar profiles and back-trajectories. The pure dust observations of SAMUM-1 in Morocco are also included.

Several authors have already reported the mixing of biomass burning aerosols in Africa with desert dust (Pélon et al., 2008; Johnson et al., 2008, on the AMMA experiment, for example). These authors reported intermediate and variable Ångström exponents (about values of $\sim 1.0$ ), that depended on the amount of each component and the aging of the smoke particles. These authors indicate a value of $\mathrm{AE}=2$ for the fine mode smoke particles, whereas a value close to zero was typical for dust coarse particles.

The fine mode fraction of the AOD $(500 \mathrm{~nm})$ was calculated using the SDA algorithm. The results for the period 28-31 January 2008 are depicted in Fig. 6a. This parameter indicates the contribution of the fine mode optical depth to the AOD at $500 \mathrm{~nm}$ wavelength. It ranges from 0.14 beginning early on 28 January (pure dust case according to the lidar), up to 0.50 on 31 January (mixed type, with dust below $1 \mathrm{~km}$ and smoke+dust aloft, similar to Fig. 2). The mean $\eta$ for each period is also included in Table 1. For both dust-dominated and marine background cases, the mean fine mode fraction (FMF) is 0.3 , whereas for the mixed cases it is about 0.45 . The maximum fine mode fraction of 0.59 is found on 3 February.

As a verification of the performance of the SDA, some cloud contaminated data are included in the last hours of 31 January. During this period the fine mode optical depth remains stable whereas the coarse mode optical depth (whose temporal behaviour is typical of clouds) varies strongly.
Figure $6 \mathrm{~b}$ shows AOD spectra for representative cases of pure dust and mixed aerosol. Note the different curvature of the dust and the mixed cases, as well as the departures in the UV and the infrared from the Angström power law (calculated in the range $440-870 \mathrm{~nm}$, dashed lines). The third order fit used for the SDA+ (considering the full $340-1550 \mathrm{~nm}$ range) is also depicted (black lines). The AOD error bars show that the discrepancies between Cimel and SSARA radiometers are within the estimated errors, and that those uncertainties cannot explain the departure from the power law. Noticeable is the curvature in the infrared ( $1550 \mathrm{~nm}$ wavelength) for the dust case, that confirms the findings in SAMUM-1 (Toledano et al., 2009) and the necessity of this channel (or the $1640 \mathrm{~nm}$ in the so called 'extended' AERONET Cimels) to investigate the radiative effects of the coarse dust particles. The third order fit better captures the curvature of the AOD spectra. The AOD $(340 \mathrm{~nm})$ for the AERONET-Cimel in SAMUM-1 did not reach the qualityassured data level 2.0. The better performance of the SAMUM-2 UV channels allows one to confirm that the AOD curvature is coherent with a third-order fit in this spectral region as well. In the period 27-30 January, the AOD spectrum has its maximum at the $500 \mathrm{~nm}$ wavelength, with a slight decrease towards the UV. This is observed both in the Cimel and SSARA data. The AOD spectra for the coarse and the fine mode derived from the SDA + are also shown in Fig. 6b. The fine mode optical depth $\left(\tau_{\text {fine }}\right)$ on 28 January is small in the visible and almost negligible at $1550 \mathrm{~nm}$, whereas the coarse mode optical depth $\left(\tau_{\text {coarse }}\right)$ dominates, with maximum at $784 \mathrm{~nm}$ wavelength. Similar spectral behaviour was found for dust aerosols in the United Arab Emirates region (O'Neill et al., 2008, see fig. 6 therein).

On the other hand, for the mixed aerosol case, the power law (linear fit) using $440-870 \mathrm{~nm}$ is a good approximationwithin the AOD uncertainties-for the entire spectral range $340-1550 \mathrm{~nm}$, showing very small differences with the third order fit. The $\tau_{\text {fine }}$ is much larger than on 28 Jan. and dominates below $380 \mathrm{~nm}$. The $\tau_{\text {coarse }}$ maximum is found at $671 \mathrm{~nm}$ wavelength. 

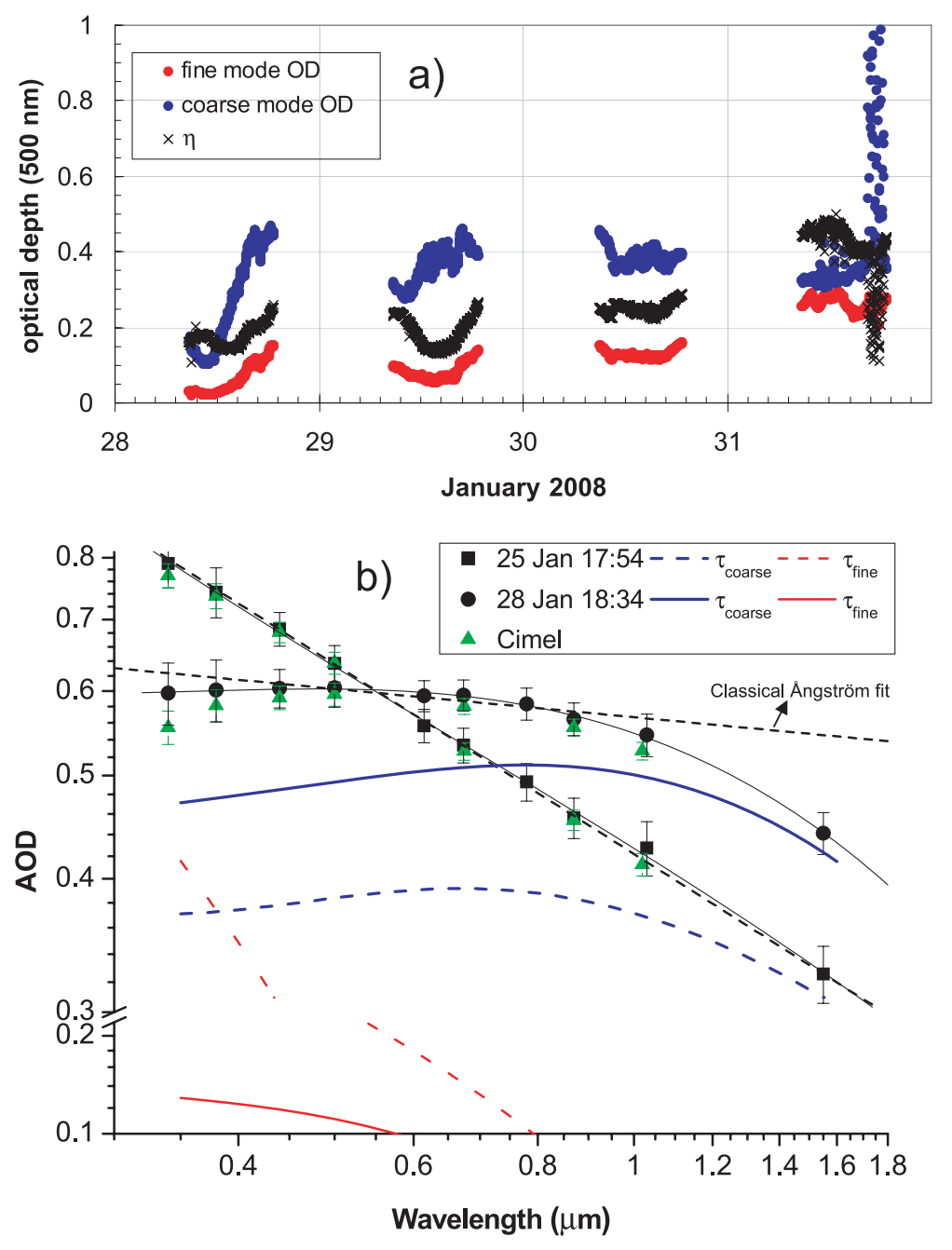

Fig. 6. (a) Separation of coarse and fine mode optical depth (O'Neill et al., 2003) for the period 28-31 January in Praia, Cape Verde. The parameter $\eta$ represents the fine mode fraction of the AOD $(500 \mathrm{~nm})$. Input AOD channels: 380-1030 nm; (b) Example spectra from SSARA radiometer of AOD by dust (28 January) and mixed aerosol (25 Jan.) in the range $340-1550 \mathrm{~nm}$. The simultaneous Cimel data are superimposed. Black dotted lines indicate the linear fit to the Ångström law in the range 440-870 nm. Black solid curved lines indicate the third-order polynomial fit. Blue and red lines show coarse and fine mode optical depths, respectively. Note the break in the vertical axis.

\subsection{Inversion-derived properties}

Columnar volume size distributions obtained with the AERONET-Cimel and the SSARA radiometer were analyzed for the periods indicated in Table 1. Note that the inversion products were AERONET level 2.0 (quality assured). For SSARA data, only the Nakajima inversion was available.

The coarse mode volume concentration is predominant in all cases, with a mean concentration of $0.17 \mu \mathrm{m}^{3} \cdot \mu \mathrm{m}^{-2}$ (particle volume per unit surface of the atmospheric column). The larger values of the coarse mode concentration are observed on the days with larger AOD. The fine mode concentration is on average $0.03 \mu \mathrm{m}^{3} \cdot \mu \mathrm{m}^{-2}$, but this fine mode concentration increases on average to $0.06 \mu \mathrm{m}^{3} \cdot \mu \mathrm{m}^{-2}$ on days with a biomass burning layer, in which case the contribution of the fine mode to the total concentration varies in the range $15-35 \%$. The fine mode almost disappears in the dust-dominated cases (mean concentration of $0.02 \mu \mathrm{m}^{3} \cdot \mu \mathrm{m}^{-2}$ ), with the fine mode contributing less than $10 \%$ to the total volume concentration.
Two retrievals are shown in Fig. 7 as examples for the two cases: dust-only (28 January), with almost no fine mode and very dominant coarse mode concentration (Fig. 7a); and dust plus smoke layers (31 January), with high concentration in both the coarse and the fine mode. As mentioned above, the contribution of the marine aerosol background is small in both cases. For the Cimel data, the difference in the fine mode is very significant between the Dubovik (AERONET) and Nakajima retrievals. The volume concentration derived from the former inversion is much higher for the dust-smoke case (Fig. 7b). The coarse mode is very similar for the two cases. These features are consistent along the data set. The SSARA retrieval reproduces almost exactly the fine mode concentration derived from the Cimel with the Nakajima code, whereas the coarse mode concentrations are in general lower. Both instruments indicate almost no fine mode in the dust-only case.

The differences encountered among the retrievals of simultaneous almucantar observations with different codes where also reported by von Hoyningen-Huene et al. (2009) for 

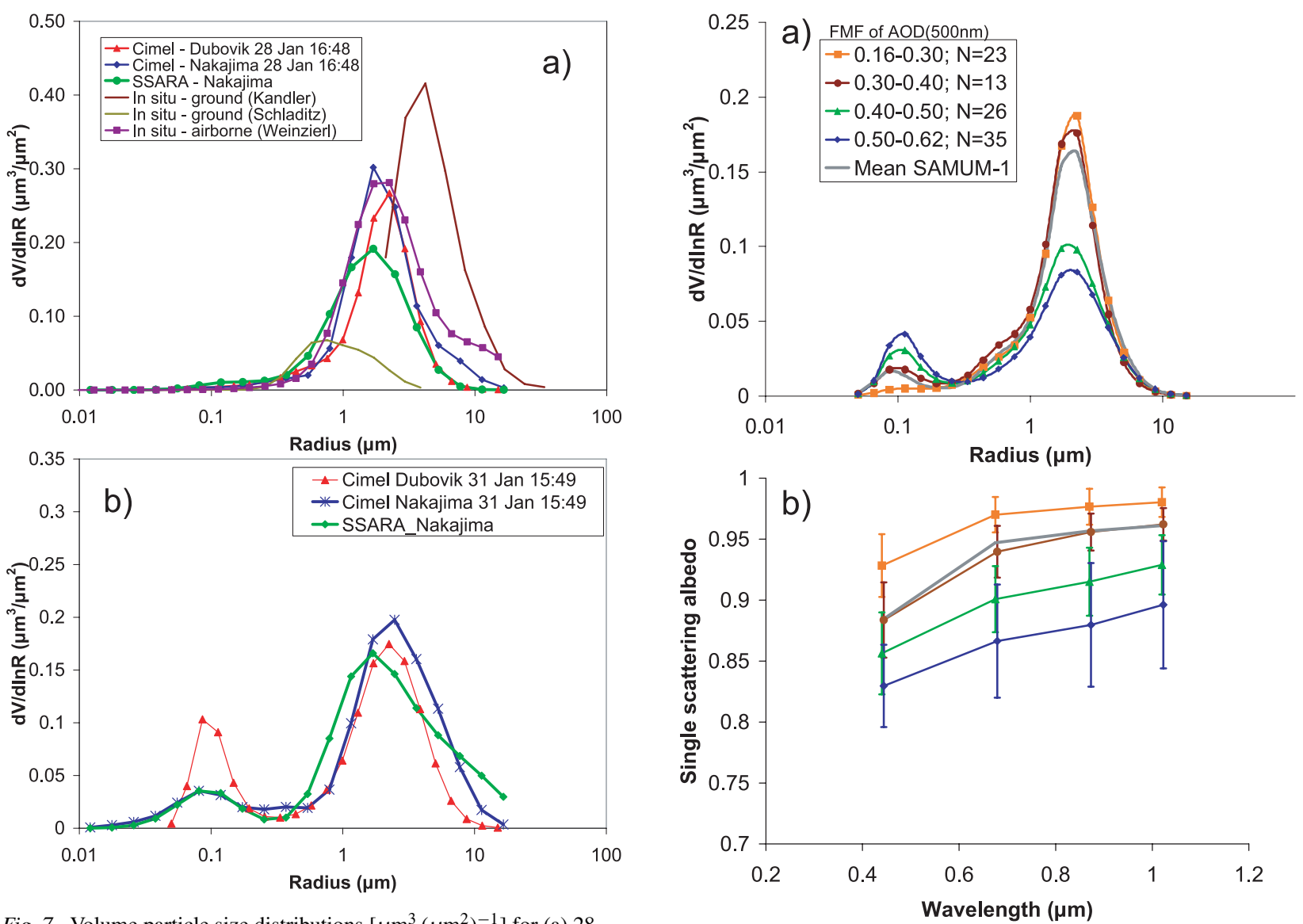

Fig. 7. Volume particle size distributions $\left[\mu \mathrm{m}^{3}\left(\mu \mathrm{m}^{2}\right)^{-1}\right]$ for (a) 28 January, dust case; and (b) 31 January, dust plus smoke case. Simultaneous retrievals for the Cimel and SSARA photometers are displayed. On 28 January, in situ size distributions at ground level (Kandler et al., 2011b; Schladitz et al., 2011) and at 599 m a.s.l. (Weinzierl et al., 2011) are shown.

the SAMUM-1 data. This disparity motivated us to validate the Sun-sky radiometer retrievals with other data, especially in situ, as was done for SAMUM-1 data (Müller et al., 2010a,b). However even more careful analysis is required for SAMUM-2 given the complexity of the vertical structure of the aerosol layers; this complicates the direct comparison of ground-level or aircraft observations with column-integrated measurements.

The AERONET inversion provides fine/coarse mode separation of the AOD for the 440, 675, 870 and $1020 \mathrm{~nm}$ wavelengths. Eck et al. (2010) use the fine mode fraction (FMF) of AOD at $675 \mathrm{~nm}$ to analyse aerosol mixtures. The choice of this channel is motivated by the wavelength of $675 \mathrm{~nm}$ being 'approximately at the centre of the downwelling solar irradiance spectrum, with $\sim 50 \%$ of the spectrally integrated flux falling above or below this wavelength'. However in the present work the $500 \mathrm{~nm}$ wavelength has been chosen, to facilitate comparisons with the SDA results. The almucantar retrievals of the Cimel were clustered

Fig. 8. (a) Volume particle size distributions and (b) single scattering albedo as a function of wavelength, averaged for intervals of the fine mode fraction of the AOD $(500 \mathrm{~nm})$. Error bars indicate $\pm 1 S T D$. The mean values obtained for these parameters in SAMUM-1 (Morocco) are also included (grey thick line).

in bins as a function of the FMF at $500 \mathrm{~nm}: 0.16-0.3,0.3-0.4$, $0.4-0.5$ and $0.5-0.62$ (the range of the SAMUM-2 data). The results in Fig. 8a indicate the prevalence of the coarse mode for smaller FMF, and the analogous but inverse behaviour for the fine mode. The number of cases is not large for each bin, but it is enough to illustrate the varying concentration and relative contribution of the fine mode and the variable mixing of 2 aerosol types.

For cases limited to an upper layer of mixed aerosols (no or little dust below $2 \mathrm{~km}$ ), the FMF ( $500 \mathrm{~nm}$ ) does not exceed 0.6 and the size distribution is still dominated by the coarse mode particles, very likely of dust origin, that are (externally) mixed with the smoke particles (Lieke et al., 2011). The retrieval results confirm that the aerosols arriving from the southeast are very likely a mixture of smoke and dust.

In general, over Cape Verde, the mixed layer from the southeast overlapped (flowed above) the pure dust aerosols transported westwards at low levels. Figure 5 also shows a mixed type for 


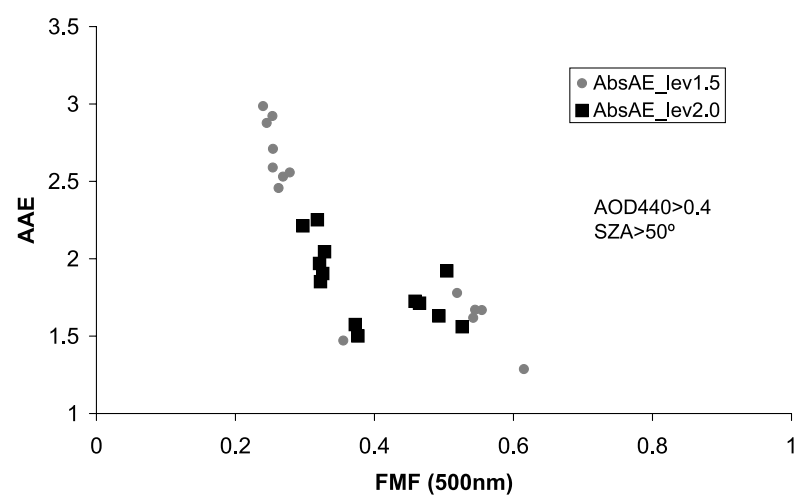

Fig. 9. Absorption Ångström exponent as a function of the FMF of the AOD $(500 \mathrm{~nm}$ ). Level 2.0 (squares) and level 1.5 (dots) data are shown. The latter are restricted to observations with $S Z A>50^{\circ}$ and $A O D(440 \mathrm{~nm})>0.4$.

the two-layer and upper-layer cases, which differs from the pure dust as observed in SAMUM-1 (Toledano et al., 2009). The (magenta) cluster of points in Fig. 5 clearly differs from both the pure dust cluster and the pure smoke cluster (Bolivian results). Coagulation and other fine-mode growth processes can shift the size distribution of biomass burning aerosol to larger particle sizes. However the low AE observed is unlikely caused by aged smoke only; the dust is the greater contribution to the low AE and FMF. The characterization of these layers, especially the absorption properties, is very relevant since this aerosol is transported across the Atlantic every dry season, affecting large areas.

The next step is to investigate how the mixture of dust and smoke affects some key optical properties, in particular the absorption. The known absorbing features of biomass burning and desert aerosols are rather different, especially with respect to the wavelength dependencies (Dubovik et al., 2002). The spectral dependence of the single scattering albedo is depicted in Fig. $8 \mathrm{~b}$ for the FMF bins described above. The larger the FMF, the smaller the SSA; this occurs because the biomass burning aerosol is more absorbing than dust. However in all cases the SSA increases with wavelength, a well-established property of dust (Dubovik et al. 2002; Petzold et al. 2009; Schladitz et al. 2009; Müller et al. 2010b). The contribution of the smoke produces increased absorption but not a change in the SSA wavelength dependence (in spite of the fact that the SSA spectral trend for smoke is opposite to that of dust, Dubovik et al. (2002)).

A similar analysis was applied to the absorption Angström exponent. This parameter, calculated across the $440-870 \mathrm{~nm}$ spectral range, is plotted as a function of the FMF $(500 \mathrm{~nm})$ in Fig. 9 . The low number of level 2.0 data points motivated us to also plot the level 1.5 data. But in order to increase the quality of these, we employed the level 2.0 criteria concerning SZA $\left(>50^{\circ}\right)$ and AOD $(440 \mathrm{~nm}>0.4)$. The result is a clear decrease of the absorption Ångström exponent with the fine mode fraction. The highest values, about 3.0, correspond to dust re- trievals on 28-29 January and are not part of the level 2.0 data set due to retrieval errors of about $7 \%$ (only slightly higher than the $6 \%$ threshold in level 2.0). This higher retrieval errors are very likely due to departures from retrieval kernel assumptions brought about by particle non-sphericity and (almucantar) spatial inhomogeneity (note that the Version 2.0 AERONET retrievals that we employed do incorporate a non-spherical component; by non-sphericity we mean deviations from this advanced but nevertheless simplified retrieval approach). The AAE values are actually in agreement with SAMUM-1 observations for pure dust (Petzold et al., 2009; Weinzierl et al., 2009) in that they consistently increase for coarse (dust) dominated observations. In contrast, as the relative contribution of the biomass burning aerosol increases, the AAE becomes lower. The lowest level 2.0 measurement of AAE is 1.50, still far from the theoretical limit of 1.0 for black carbon (Bohren and Huffman, 1983).

\subsection{Case study: dust}

The aerosol optical and microphysical properties derived from sun-sky radiometers in SAMUM-1 were compared with the information (ground-based and airborne) provided by the in situ instruments. Shape-dependent (Müller et al., 2010a) and shapeindependent properties (Müller et al., 2010b) were analysed. The experimental conditions, with a single and homogeneous dust layer in many cases, were more favourable for such analysis than in SAMUM-2. The SAMUM-2 period with stronger dust predominance (27-30 January) is however suitable for a comparison of more spatially invariant intensive properties, like effective radii, Ångström exponents and single scattering albedo. More difficulties are encountered with extensive properties like the particle size distributions, because the vertical distribution of the aerosol is critical for a comparison of in situ and columnar observations.

The dust episode on 27-30 January was characterized by the arrival of a Saharan air mass at altitudes below $1.5 \mathrm{~km}$ with very high and wavelength independent extinction coefficients (up to $1.0 \mathrm{~km}^{-1}$ ) according to the lidar data (Groß et al., 2011a). On 29 and 30 January the largest values of ground mass concentration (Total Suspended Particles and PM10) were observed (Kandler et al., 2011a).

The effective radii (Hansen and Travis, 1974) for the fine and the coarse mode were calculated from the in situ particle size distribution measurements at ground level. These were measured with a combination of a Differential Mobility Particle Sizer (DMPS) for the mobility size range of 26-800 nm and an Aerodynamic Particle Sizer (APS) for the aerodynamic size range of $570 \mathrm{~nm}$ to $10 \mu \mathrm{m}$ (Schladitz et al., 2011), as well as with optical microscopy following particle collection with a single stage nozzle impactor (SSI) with a size range of 4-20 $\mu \mathrm{m}$ projected area diameter and a free-wing impactor (FWI) with a size range 14-160 $\mu \mathrm{m}$ (Kandler et al., 2011b). The inversion of Sun photometer and almucantar radiance data (Dubovik et al., 
Fig. 10. Effective radii for the fine and the coarse mode of the particle size distributions at Praia (Cape Verde) from 25 to 31 January, (orange), sun-sky full inversion data from the AERONET-Cimel (brown) and estimation by the SDA (red) are provided. Coarse mode: in situ (purple), AERONET-Cimel (green) and SDA (blue). 2008. Fine mode: in situ measurements

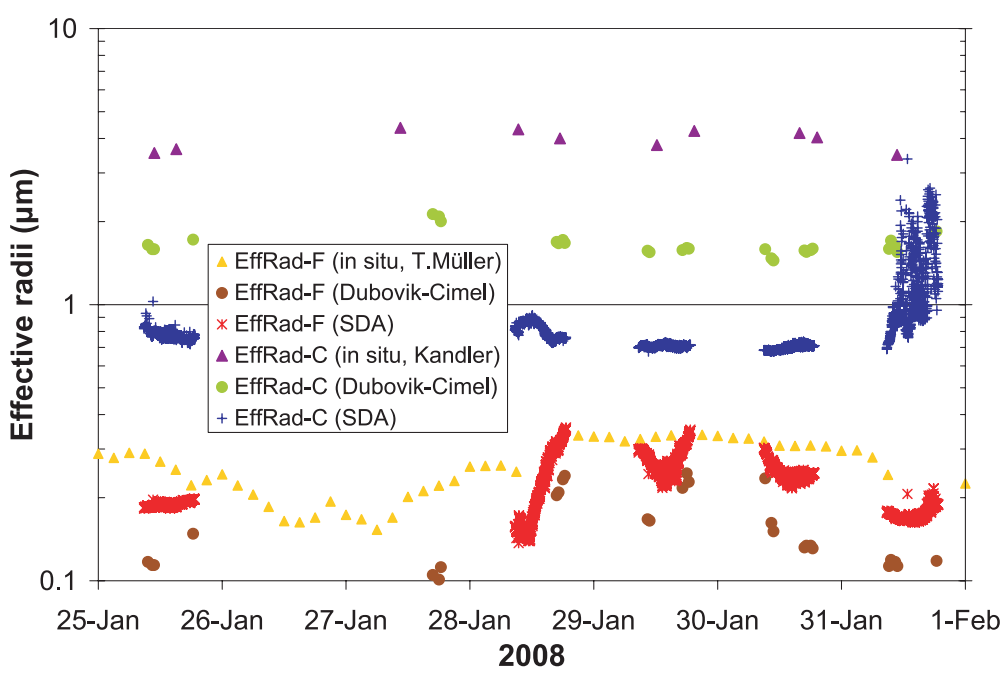

2006) also provides columnar size distributions and therefore effective radii. Finally we have also considered the fine and coarse mode effective radii provided by, respectively, the SDA/FMC algorithm (O'Neill et al., 2003, 2005) and the SDA+ algorithm (O’Neill et al., 2008).

The results are depicted in Fig. 10. The $R_{\text {eff }}-\mathrm{F}$ time series from the SDA/FMC retrieval and in situ measurements follow a roughly similar trend. $R_{\text {eff }}-\mathrm{F}$ is about 0.2 on the 25 th, then increases up to $0.35 \mu \mathrm{m}$ on the 28th (arrival of dust), and goes down again on the 31st (arrival of dust-smoke layers aloft). At the end of 28 January both SDA/FMC and in situ yield $R_{\text {eff }}-\mathrm{F}$ of $0.33 \mu \mathrm{m}$. The Dubovik inversion values are underestimated relative to the in situ data, although they still exhibit a maximum on 28-19 January and decrease on 30-031 January. We should note that the nominally better performance of the SDA/FMC algorithm may be fortuitous since the technique has never been validated in a coarse mode dominated environment. The coarse mode effective radii from in situ data (about $3.9 \mu \mathrm{m}$ ) are two times larger than those from AERONET inversions $(1.7 \mu \mathrm{m})$ and four times larger than the SDA+ retrieval $(0.85 \mu \mathrm{m})$. These findings are very similar to the differences in these parameter encountered during SAMUM-1 (Müller et al., 2010b, see Table 3).

The discrepancies in the effective radii can be better understood by looking at the associated size distributions. On 28 January the vertical distribution within the dust layer was not homogeneous, with extinction coefficients $(532 \mathrm{~nm})$ ranging from 0.07 to 1.03 and with much higher extinction values at lower altitudes. Therefore the comparison of the volume columnar size distribution from in situ and sun photometer data shown in Fig. 7a must be treated with caution when comparing absolute values. In this figure, the size distributions (ground level) at 18UTC from Kandler et al. (2011b) are used for the coarse mode and the data collected by Schladitz et al. (2011)—with PM10 inlet and upper particle radius limit of $3.8 \mu \mathrm{m}$ - are used for the fine mode. The two curves are obtained with different inlet cutoff and technique (geometrical and aerodynamic), therefore a mismatch in the overlap region is to be expected. At ground level, the extinction coefficient $(500 \mathrm{~nm})$ was 0.75 (Müller et al., 2011). Airborne in situ size distribution from Weinzierl et al. (2011) is also shown. It was collected around 18UTC at $599 \mathrm{~m}$ a.s.l. At that altitude the extinction coefficient $(532 \mathrm{~nm}$ ) was 0.37 (Groß et al., 2011b). The operational Dubovik retrieval of the AERONET-Cimel and the Nakajima inversion results (Cimel and SSARA) are supermimposed. The AOD $(500 \mathrm{~nm})$ was 0.58 . To compare all the size distributions, the in situ data were converted into columnar values using a scale height that converted the measured extinction coefficient at the corresponding altitude into the observed AOD.

The shape of the distributions is clearly different with respect to the position of the fine and coarse modes. The disagreement between in situ at ground level and photometer essentially shows the same features observed with SAMUM-1 data (Müller et al., 2010b, see Fig. 4). The coarse mode from in situ data peaks at almost double radius $(4.2 \mu \mathrm{m})$ than the sun photometers $(1.7-2.2 \mu \mathrm{m}$ depending on the retrieval). Furthermore, the secondary mode at ground level around $0.75 \mu \mathrm{m}$ is not observed in the columnar data. Much better agreement was encountered between the sun photometer retrievals (in particular the Nakajima retrieval) and the airborne measurements. The coarse mode peaks in both cases about $2.2 \mu \mathrm{m}$ and the derived coarse mode effective radii are close (1.69 and $1.87 \mu \mathrm{m}$, respectively). However the coarse mode from the Dubovik and the Nakajima inversions diverge from the in situ for sizes above $2.5 \mu \mathrm{m}$ radius and seem to miss a relevant portion of the coarse mode distribution.

The differences among the various sunphotometer retrievals and the airborne measurement were small compared to the differences with the in situ size distribution at ground level. It can be expected a decrease in large particle concentration with increasing altitude due to the local contribution, even for sizes below $10 \mu \mathrm{m}$ (see fig. 6/7 in Kandler et al., 2011b). In this case study, the vertical inhomogeneities shown by the lidar and the 


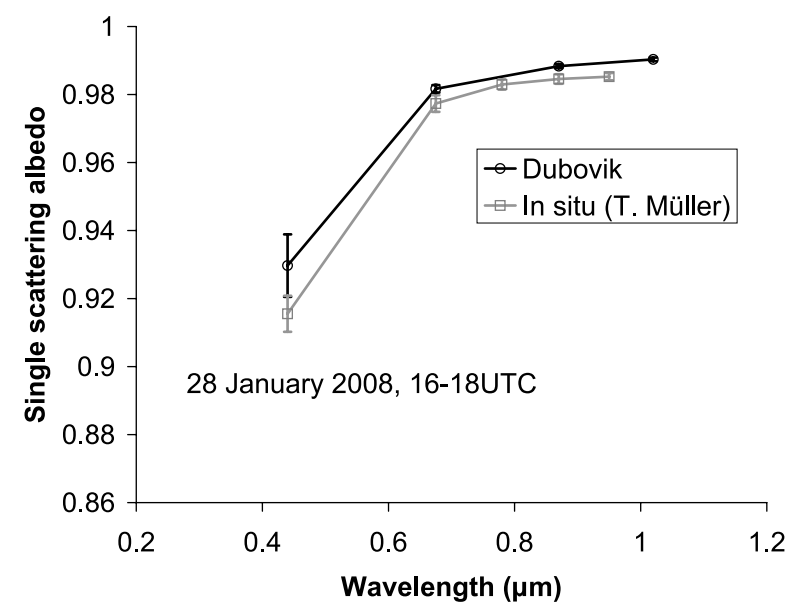

Fig. 11. Daily mean single scattering albedo as a function of wavelength on 28 January, 2008 at Praia. Bars indicate \pm 1 STD. In situ data are from ground-based measurements of scattering and absorption coefficients (Müller et al., 2011); Dubovik retrievals calculated from the AERONET- Cimel sun photometer observations.

in situ (airborne and ground) make the comparison with sun photometer difficult.

Aside from the observed significant differences in coarse mode distribution with altitude, the discrepancy between in situ and sunphotometry may also be due to the insensitivity of such inversions to large, coarse mode particles (basically the only large coarse mode particle information comes from small scattering angles for which the radiance measurements are typically cut off due to concerns of instrumental stray light scattering). The forward modeling analysis of sky radiances by Gasteiger et al. (2011) also indicated an underestimate of coarse-mode particle numbers from the Dubovik inversion when comparing computed almucantar radiances with measured radiances. Nevertheless the better agreement in this case among airborne and sun photometers is a significant result as compared to SAMUM1 (much larger coarse mode differences were reported in that campaign).

Finally, the single scattering albedo daily mean on 28 January is depicted in Fig. 11 as a function of wavelength. The in situ observations of SSA at ground level (Müller et al., 2009,2011) are compared to the Dubovik retrievals of the AERONET-Cimel sun-sky data. Bear in mind that the SSA absolute uncertainty is 0.03 for the Cimel data. The vertical bars indicate the daily standard deviation. The agreement is good with respect to the absolute values (differences within the uncertainties) and also with respect to the wavelength dependence (as it was also in SAMUM-1; Müller et al., 2010b, see Fig. 8).

\section{Conclusions}

A complex structure of layers at different altitudes and of differing origin, transporting different aerosol types, was observed during SAMUM-2 thanks to lidar profiles and sun photometer columnar measurements. The aerosol optical and microphysical properties derived from the sun-sky photometers deployed in SAMUM-2 allowed the characterization of pure cases (dust, marine) as well as mixtures of dust and smoke originating in West-central Africa, where the biomass burning season was active. The measurement period was separated into episodes corresponding to different aerosol types and layers as determined from sunphotometry parameters such as AOD and the Ångström exponent, as well as lidar profiles.

The curvature of the AOD spectra for the dust cases is not captured by the simple (fixed slope) Ångström power law, therefore the wavelength range used in its calculation results in significant differences. A higher order fit, such as the third order fit used in the $\mathrm{SDA}+$, is much more suitable for the AOD representation in the full 340-1550 nm spectral range. The spectral maximum coarse mode optical depth during the dust dominated case of January 28 was found to be $\sim 780 \mathrm{~nm}$. The AOD maximum is found at $\sim 500 \mathrm{~nm}$.

The fine mode fraction of the AOD, derived from either the SDA or the AERONET retrieval, is a useful tool for the monitoring of aerosol mixtures from sunphotometry. It was shown that the dust+smoke type is in general more absorbing than dust, with smaller single scattering albedo for larger fine mode fractions. However the contribution of dust to these mixture is such that the SSA wavelength dependence of the mixture still exhibits the typical signature of dust, that is, it increases with wavelength.

The large values of the spectral slope of the absorption optical depth, represented by the Absorption Ångström exponent, confirms the SAMUM-1 findings about the rapid increase of the absorption optical depth towards the UV wavelengths for desert dust. The larger the fine mode fraction (larger smoke contribution), the smaller the Absorption Ångström exponent.

The comparison of the Sun photometer retrievals of dust properties with in situ observations of size distributions and single scattering albedo revealed some differences with respect to SAMUM-1 results. The column-integrated size distributions from sun photometers agreed well with the shape of the airborne in situ data, exhibiting similar coarse mode effective radii. The in situ size distributions at ground level likely have significant contribution from local sources and did not agree with the sun photometer or the airborne observations, especially in the position of the coarse mode. However, the sun photometer inversions seemed to miss part of the coarse particle distribution and the coarse-mode effective radius is therefore smaller than provided by the airborne in situ observations. The single scattering albedo, on the other hand, seems to be well represented by the AERONET inversion.

\section{Acknowledgments}

The authors thank B. Holben and the AERONET staff for their effort in establishing and maintaining the Praia site. We also 
thank V. Cachorro for the use of RIMA calibration equipment and E. Cuevas for the Izaña calibration platform. The present study was supported by the German Research Foundation (DFG) within the Research Group SAMUM.

\section{References}

Ansmann, A., Petzold, A., Kandler, K., Tegen, I., Wendisch, M. and coauthors. 2011. Saharan Mineral Dust Experiments SAMUM-1 and SAMUM-2: what have we learned? Tellus 63B, this issue.

Bergstrom, R. W., Pilewskie, P., Russell, P. B., Redemann, J., Bond, T. C. and co-authors. 2007. Spectral absorption properties of atmospheric aerosols. Atmos. Chem. Phys. 7(23), 5937-5943.

Bohren, C. F. and Huffman, D. R. 1983. Absorption and Scattering of Light by Small Particles. Wiley and Sons, New York, 530 pp.

Dubovik, O., Holben, B., Eck, T., Smirnov, A., Kaufman, Y. and coauthors. 2002. Variability of absorption and optical properties of key aerosol types observed in worldwide locations. J. Atmo. Sci. 59, 590-608.

Dubovik, O., Sinyuk, A., Lapyonok, T., Holben, B. N., Mishchenko, M. and co-authors. 2006. Application of spheroid models to account for aerosol particle nonsphericity in remote sensing of desert dust. $J$. Geophys. Res. 111, D11208.

Dubovik, O., Smirnov, A., Holben, B. N., King, M. D., Kaufman, Y. J. and co-authors. 2000. Accuracy assessments of aerosol optical properties retrieved from Aerosol Robotic Network (AERONET) Sun and sky radiance measurements. J. Geophys. Res. 105, 97919806.

Eck, T. F., Holben, B. N., Siniuk, A., Pinker, R. T., Goloub, P. and co-authors. 2010. Climatological aspects of the optical properties of fine/coarse mode aerosol mixtures. J. Geophys. Res. 115, D19205.

Eck, T., Holben, B., Reid, J., Dubovik, O., Smirnov, A. and coauthors. 1999. The wavelength dependence of the optical depth of biomass burning, urban and desert dust aerosols. J. Geophys. Res. 104, 31 333-31350.

Freudenthaler, V., Esselborn, M., Wiegner, M., Heese, B., Tesche, M. and co-authors. 2009. Depolarization ratio profiling at several wavelengths in pure Saharan dust during SAMUM 2006. Tellus 61B, 165-179.

Gasteiger, J., Wiegner, M., Gross, S., Freudenthaler, V., Toledano, C. and co-authors. 2011. Modeling lidar-relevant optical properties of complex mineral dust aerosols. Tellus 63B, this issue.

Goudie, A. and Middleton, N. 2001. Saharan dust storms: nature and consequences. Earth-Sci. Rev. 56, 179-204.

Groß, S., Freudenthaler, V., Wiegner, M., Gei, A., Tesche, M. and coauthors. 2011a. Characterization of the planetary boundary layer during SAMUM-2 by means of lidar measurements. Tellus $\mathbf{6 3 B}$, this issue.

Groß, S., Tesche, M., Freudenthaler, V., Toledano, C., Wiegner, M. and co-authors. 2011b. Characterization of Saharan dust, marine aerosols and a mixture of biomass burning aerosols and dust by means of multi-wavelength depolarization- and Raman-measurements during SAMUM 2. Tellus 63B, this issue.

Hansen, J. and Travis, L. 1974. Light scattering in planetary atmospheres. Space Sci. Rev. 16, 527-610.

Haywood, J., Francis, P., Dubovik, O., Glew, M. and Holben, B. 2003. Comparison of aerosol size distributions, radiative properties, and op- tical depths determined by aircraft observations and Sun photometers during SAFARI 2000. J. Geophys. Res. 108(D13), 8471.

Haywood, J. M., Pelon, J., Formenti, P., Bharmal, N., Brooks, M. and coauthors. 2008. Overview of the dust and biomass-burning experiment and African Monsoon multidisciplinary analysis special observing period-0. J. Geophys. Res. 113, D00C17.

Heintzenberg, J. 2009. The SAMUM-1 experiment over Southern Morocco: overview and introduction. Tellus $\mathbf{6 1 B}, 2-11$.

Hess, M., Koepke, P. and Schult, I. 1998. Optical properties of aerosols and clouds: the software package OPAC. Bull. Am. Met. Soc. 79(5), 831-844.

Holben, B., Eck, T., Slutsker, I., Tanré, D., Buis, J. and co-authors. 1998. AERONET- a federated instrument network and data archive for aerosol characterization. Remote Sens. Environ. 66, 1-16.

Holben, B., Tanre, D., Smirnov, A., Eck, T., Slutsker, I. and co-authors. 2001. An emerging ground-based aerosol climatology: aerosol optical depth from AERONET. J. Geophys. Res. 106, 12067-12097.

Johnson, B. T., Osborne, S. R. and Haywood, J. M. 2008. Aircraft measurements of biomass-burning aerosols over West Africa during DABEX. J. Geophys. Res. 113, D00C06.

Kandler, K., Lieke, K., Benker, N., Emmel, C., Küpper, M. and coauthors. 2011a. Electron microscopy of particles collected at Praia, Cape Verde, during the Saharan Mineral dust experiment: particle chemistry, shape, mixing state and complex refractive index. Tellus 63B, this issue.

Kandler, K., Schütz, L., Jäckel, S., Lieke, K., Emmel, C. and co-authors. 2011b. Ground-based off-line aerosol measurements at Praia, Cape Verde, during the Saharan Mineral Dust Experiment: microphysical properties and mineralogy. Tellus $63 \mathrm{~B}$, this issue.

Kaufman, Y. J., Koren, I., Remer, L. A., Tanré, D., Ginoux, P. and coauthors. 2005. Dust transport and deposition observed from the TerraModerate Resolution Imaging Spectroradiometer (MODIS) spacecraft over the Atlantic Ocean. J. Geophys. Res. 110, D10S12.

Knippertz, P., Tesche, M., Heinold, B., Kandler, K., Toledano, C. and co-authors. 2011. Dust mobilization and aerosol transport from West Africa to Cape Verde-a meteorological overview of SAMUM-2. Tellus 63B, this issue.

Li, Z., Blarel, L., Podvin, T., Goloub, P., Buis, J. P. and co-authors. 2008. Transferring the calibration of direct solar irradiance to diffuse-sky radiance measurements for CIMEL Sun-sky radiometers. Appl. Opt. 47(10), 1368-1377.

Lieke, K., Kandler, K., Emmel, C., Petzold, A., Weinzierl, B. and coauthors. 2011. Particle chemical properties in the vertical column based on aircraft observations in the vicinity of Cape Verde islands. Tellus 63B, this issue.

Liu, D., Wang, Z., Liu, Z., Winker, D. and Trepte, C. 2008. A height resolved global view of dust aerosols from the first year CALIPSO lidar measurements. J. Geophys. Res. 113, D16214.

McConnell, C. L., Highwood, E. J., Coe, H., Formenti, P., Anderson, B. and co-authors. 2008. Seasonal variations of the physical and optical characteristics of Saharan dust: results from the Dust Outflow and Deposition to the Ocean (DODO) experiment. J. Geophys. Res. 113, D14S05.

Mishchenko, M. I., Travis, L. D., Kahn, R. A. and West, R. A. 1997. Modeling phase functions for dustlike tropospheric aerosols using a shape mixture of randomly oriented polydisperse spheroids. J. Geophys. Res. 102(D14), 16831-16847. 
Müller, D., Ansmann, A., Freudenthaler, V., Kandler, K., Toledano, C. and co-authors. 2010a. Mineral dust observed with AERONET Sun photometer, Raman lidar, and in situ instruments during SAMUM 2006: shape-dependent particle properties. J. Geophys. Res. 115, D11207.

Müller, D., Weinzierl, B., Petzold, A., Kandler, K., Ansmann, A. and co-authors. 2010b. Mineral dust observed with AERONET Sun photometer, Raman lidar, and in situ instruments during SAMUM 2006: shape-independent particle properties. J. Geophys. Res. 115, D07202.

Müller, T., Schladitz, A., Massling, A., Kaaden, N., Kandler, K. and coauthors. 2009. Spectral absorption coefficients and imaginary parts of refractive indices of Saharan dust during SAMUM-1. Tellus 61B, 79-95.

Müller, T., Schladitz, A. and Wiedensohler, A. 2011. Spectral particle absorption coefficients, single scattering albedos, and imaginary parts of refractive indices from ground based in-situ measurements at Cape Verde Island during SAMUM-2. Tellus 63B, this issue.

Myhre, G. 2009. Consistency between satellite-derived and modeled estimates of the direct aerosol effect. Science 325, 187-190.

Nakajima, T., Tonna, G., Rao, R., Boi, P., Kaufman, Y. 1996. Use of sky brightness measurements from ground for remote sensing of particulate polydispersions. Appl. Opt. 35, 15, 2672-2686.

Olmo, F., Quirantes, A., Lara, V., Lyamani, H. and Alados-Arboledas, L. 2008. Aerosol optical properties assessed by an inversion method using the solar principal plane for non-spherical particles. J. Quantit. Spectrosc. Radiat. Transfer 109, 1504-1516.

O’Neill, N. T., Eck, T. F., Reid, J. S., Smirnov, A. and Pancrati, O. 2008. Coarse mode optical information retrievable using ultraviolet to shortwave infrared Sun photometry: application to United Arab Emirates Unified Aerosol Experiment data. J. Geophys. Res. 113, D05212.

O’Neill, N. T., Eck, T. F., Smirnov, A., Holben, B. N. and Thulasiraman, S. 2003. Spectral discrimination of coarse and fine mode optical depth. J. Geophys. Res. 108(D17), 45-59.

O’Neill, N. T., Thulasiraman, S., Eck, T. F. and Reid, J. S. 2005. Robust optical features of fine mode size distributions: application to the Québec smoke event of 2002. J. Geophys. Res. 110, D11207.

Otto, S., Bierwirth, E., Weinzierl, B., Kandler, K., Esselborn, M. and coauthors. 2009. Solar radiative effects of a Saharan dust plume observed during SAMUM assuming spheroidal model particles. Tellus 61B, 270-296.

Pélon, J., Mallet, M., Mariscal, A., Goloub, P., Tanre, D. and coauthors. 2008. Microlidar observations of biomass burning aerosol over Djougou (Benin) during African Monsoon Multidisciplinary Analysis Special Observation Period 0: Dust and Biomass-Burning Experiment. J. Geophys. Res. 113, D00C18.

Petzold, A., Rasp, K., Weinzierl, B., Esselborn, M., Hamburger, T. and co-authors. 2009. Saharan dust absorption and refractive index from aircraft-based observations during SAMUM 2006. Tellus 61B, 118-130.

Pinker, R. T., Liu, H., Osborne, S. R. and Akoshile, C. 2010. Radiative effects of aerosols in sub-Sahel Africa: dust and biomass burning. $J$. Geophys. Res. 115, D15205.

Prospero, J. M., Ginoux, P., Torres, O., Nicholson, S. E. and Gill, T. E. 2002. Environmental characterization of global sources of atmo- spheric soil dust identified with the NIMBUS 7 Total Ozone Mapping Spectrometer (TOMS) absorbing aerosol product. Rev. Geophys. 40(1), 1002.

Randles, C. A. and Ramaswamy, V. 2010. Direct and semi-direct impacts of absorbing biomass burning aerosol on the climate of southern Africa: a Geophysical Fluid Dynamics Laboratory GCM sensitivity study. Atmos. Chem. Phys. 10, 9819-9831.

Reid, J. S., Kinney, J. E., Westphal, D. L., Holben, B. N., Welton, E. J. and co-authors. 2003. Analysis of measurements of Saharan dust by airborne and ground-based remote sensing methods during the Puerto Rico Dust Experiment (PRIDE). J. Geophys. Res. 108, 8586.

Remer, L. A. and Kaufman, Y. J. 2006. Aerosol direct radiative effect at the top of the atmosphere over cloud free ocean derived from four years of MODIS data. Atmos. Chem. Phys. 6, 237-253.

Russell, P. B., Bergstrom, R. W., Shinozuka, Y., Clarke, A. D., DeCarlo, P. F. and co-authors. 2010. Absorption Angstrom Exponent in AERONET and related data as an indicator of aerosol composition. Atmos. Chem. Phys. 10,3, 1155-1169.

Schladitz, A., Müller, T., Nowak, A., Kandler, K., Lieke, K. and coauthors. 2011. In situ aerosol characterization at Cape Verde. Part 1: particle number size distributions, hygroscopic growth and state of mixing of the marine and Saharan dust aerosol. Tellus 63B, this issue.

Schladitz, A., Müller, T., Kaaden, N., Massling, A., Kandler, K. and coauthors. 2009. In situ measurements of Optical Properties at Tinfou (Morocco) during the Saharan Mineral Dust Experiment SAMUM 2006. Tellus 61B, 64-78.

Smirnov, A., Holben, B., Kaufman, Y., Dubovik, O., Eck, T. and coauthors. 2002. Optical properties of atmospheric aerosol in maritime environments. J. Atmos. Sci. 59, 501-523.

Solomon, S., Qin, D., Manning, M., Alley, R., Berntsen, T. and coauthors. 2007. Cambridge University Press, New York, USA, chapter Technical Summary Contribution of Working Group 1 to the 4th Assessment Report of the Intergovernmental Panel on Climate Change, p. 21-87.

Tanré, D., Haywood, J., Pelon, J., Léon, J., Chatenet, B. and co-authors. 2003. Measurement and modeling of the Saharan dust radiative impact: overview of the Saharan Dust Experiment (SHADE). J. Geophys. Res. 108(D18), 8574.

Toledano, C., Wiegner, M., Garhammer, M., Seefeldner, M., Gasteiger, J. and co-authors. 2009. Spectral aerosol optical depth characterization of desert dust during SAMUM 2006. Tellus 61B, 216-228.

von Hoyningen-Huene, W., Dinter, T., Kokhanovsky, A., Burrows, J. and M., D. 2009. Measurements of desert dust optical characteristic at Porte au Sahara during SAMUM. Tellus 61B, 206-215.

Weinzierl, B., Petzold, A., Esselborn, M., Wirth, M., Rasp, K. and coauthors. 2009. Airborne measurements of dust layer properties, particle size distribution and mixing state of Saharan dust during SAMUM 2006. Tellus 61B, 96-117.

Weinzierl, B., Sauer, D., Esselborn, M., Petzold, A., Veira, A. and co-authors. 2011. Microphysical and optical properties of dust and tropical biomass burning aerosol layers in the Cape Verde regionan overview of the airborne in-situ and lidar measurements during SAMUM-2. Tellus 63, this issue. 